\title{
FutureJournal
}

\section{Novas Abordagens para o Uso das Ferramentas Clássicas de Planejamento de Cenários}

\author{
Ricardo Baliero Fischer \\ Mestre em Gestão Empresarial pela Fundação Getúlio Vargas (FGV), Brasil
}

\section{RESUMO}

O futuro está para ser construído - é múltiplo e incerto. Dentro das ciências sociais, cenários podem ser definidos como descrição de uma situação futura e de um curso de eventos que permita o movimento de uma posição original para essa situação futura. Atualmente, existe à disposição uma enormidade de métodos e ferramentas para construção de cenários, entre eles métodos de abordagem essencialmente racionalista, como o de Michel Godet. A proposta deste trabalho é utilizar o método hipotético-dedutivo para reduzir, a partir do Método de Cenários de Michel Godet e de suas ferramentas, a complexidade no processo de construção de cenários, mas ao mesmo tempo manter a robustez das conclusões. Para isso, foram propostas duas abordagens: (1) integrar em apenas uma etapa a análise estrutural e a análise de impactos cruzados, a primeira resultando automaticamente do preenchimento da última; (2) utilizar o conceito de redes bayesianas como forma de integrar a matriz de impactos cruzados e a análise morfológica. Ambas as abordagens visam reduzir a quantidade de informações necessárias para alimentar as ferramentas e melhoram o critério de feedback, resultando em maior agilidade no processo e melhor visão holística do sistema. Cientificamente, essas abordagens abrem um novo campo para estudos de planejamento de cenários já que se apropriam do conceito de redes bayesianas, muito utilizado em outras áreas do conhecimento (inteligência artificial, estudos geológicos, diagnósticos médicos, classificação de padrões, etc.) e o trazem para o campo das ciências sociais.

PALAVRAS-CHAVE: Cenários. Análise estrutural. Análise de impactos cruzados. Redes bayesianas. Análise morfológica. 


\section{FutureJournal}

FUTURE STUDIES RESEARCH JOURNAL:

TRENDS AND STRATEGIES

\section{New approaches for the use of the classical tools of scenario planning}

\section{ABSTRACT}

The future is to be built - is multiple and uncertain. Within the social sciences, scenarios can be defined as a description of a future situation and a course of events that allow move from a primary position toward this future situation. Currently, there is a multiplicity of methods and tools available for building scenarios, including methods of an essentially rationalist approach, as Michel Godet's method. The purpose of this work is to use the hypotheticaldeductive method to reduce, starting from Michel Godet's Scenario Method and its tools, the complexity of the scenario-building process while maintaining the robustness of the findings. For this purpose, it is proposed two different approaches: (1) to integrate, in one step, the structural analysis and the cross-impact matrix so the first one derives automatically while filling the last one; (2) to use the concept of bayesian networks as a method to integrate the crossimpact matrix and the morphological analysis. Both approaches aim to reduce the amount of information needed to feed the tools and improve the feedback criteria, resulting in greater flexibility during the process and better holistic view of the system. Scientifically, these approaches open a new field of studies in scenario planning as it appropriates the concept of bayesian networks, widely used in other areas of knowledge (artificial intelligence, geological studies, medical diagnostics, pattern classification, etc.), and bring it to the field of social sciences.

KEY-WORDS: Scenarios. Structural analysis. Cross-impact analysis. Bayesian networks. Morphological analysis. 


\section{INTRODUÇÃO}

O desejo de conhecer o futuro existe desde o início da humanidade. $\mathrm{Na}$ busca desse conhecimento, o homem acreditava em quem the pudesse prever o futuro. É possível perceber, em distintos momentos da história, governantes em busca de informações que pudessem minimizar o risco de suas decisões (Marcial \& Grumbach, 2005).

Mas, afinal, o que é o futuro? A verdade é que o futuro é múltiplo, incerto e não está escrito em lugar algum - ele está para ser construído. Se o homem tivesse a certeza dos acontecimentos futuros, perderia sua liberdade e seu propósito: a esperança de um futuro desejado (Godet \& Roubelat, 1996). Porém, para lidar com o futuro, é preciso aceitar que se está lidando com incertezas. No curto prazo, projeções de tendências costumam funcionar muito bem. Porém, no médio/longo prazo, as incertezas aumentam e apenas o estudo de tendências não se tem mostrado muito eficaz. Partindo da aceitação dessa incapacidade do homem em prever o futuro é que nasceram os estudos de cenários, que exploraram configurações de variáveis de forma a criar vários futuros possíveis. Schnaars (1987) comparou resultados de estudos econométricos com estudos que utilizam métodos de cenários e acabou por concluir que o método de cenários obteve claras vantagens sobre os métodos projetivos tradicionais. Godet e Roubelat (1996) analisaram previsões realizadas anos antes e constataram que os erros foram baseados principalmente em dois itens: a superestimação dos impactos dos avanços tecnológicos e a subestimação de fatores inerciais, como os comportamentos e as estruturas sociais.

Dentro das ciências sociais, cenários podem ser definidos como uma descrição de uma situação futura e de um curso de eventos que permita mover de uma situação original para essa situação futura (Godet \& Roubelat, 1996). Ou ainda, é poder visualizar futuros possíveis, particularmente os derivados e apresentados por métodos sistemáticos e os que se definem pela visão holística das circunstâncias em questão (Miles, 2005). 
O planejamento por cenários (ou estudo prospectivo) é mais do que um método, é um processo. Sua característica marcante é a necessidade de ser feito de forma participativa, em que papel principal no processo cabe aos especialistas, os únicos capazes de manejar conhecimentos teóricos e práticos e de usar sua sensibilidade para elaborar visões coerentes de futuro (Marques, 1988). Ao montar-se esse modelo simplificado da realidade por meio das informações estruturadas de especialistas, na prospectiva não se desprezam as outras formas de análise. Ao contrário, busca-se utilizar todos os tipos de análise de forma que possam conter variáveis quantitativas e qualitativas.

Atualmente, tem-se à disposição uma enormidade de métodos e ferramentas para construção de cenários. Há métodos de abordagem intuitiva, como o de Pierre Wack (1985a; 1985b) e de seus discípulos Peter Schwartz (2000) e Kees van der Heijden (2004), como há métodos de abordagem essencialmente racionalista, como o de Michel Godet (1993). Também são muitas as ferramentas apropriadas por esses métodos, como a análise morfológica, de característica mais intuitiva, e as inúmeras variações de uso da matriz de impactos cruzados, que tem uma abordagem mais quantitativa.

A existência dessa grande variedade de métodos e ferramentas pode ser explicada levando-se em conta que, devido à natureza tendenciosamente determinística do ser humano, é sempre complicado dar crédito a métodos que afirmam existirem várias respostas possíveis. Portanto, acaba ocorrendo uma busca incessante por mais robustez, no processo e nos resultados, em cada novo método apresentado, com o objetivo de lhe conferir mais credibilidade. Muitas vezes, na busca por essa robustez, em um mesmo método podem estar presentes várias ferramentas de características distintas, o que pode elevar a complexidade da análise. Soma-se a isso o fato de que há disponíveis no mundo informações abundantes e incompletas (Godet \& Roubelat, 1996), mas as decisões devem ser tomadas rapidamente. Por tudo isso, os métodos de construção de cenários devem ter um caráter seletivo. Iniciar um trabalho de construção de cenários tendo um foco muito próximo do modelo aumenta em muito as chances de perder pontos-chave na análise dos determinantes 
de futuro. Para trabalhar com cenários, é necessário ter a visão macro do modelo para depois entrar nos detalhes (Duncan \& Wack, 1994). Portanto, as ferramentas e os métodos utilizados devem lidar com o mínimo de informações possíveis e ser simples o bastante para que os resultados possam ser facilmente assimilados pelos tomadores de decisões. Ao mesmo tempo, devem conferir robustez e credibilidade aos resultados alcançados.

Dentro desse contexto, a proposta deste trabalho, tomando como base conceitual a estrutura do Método de Cenários proposto por Michel Godet por ser o mais estruturado e rigoroso dentre os métodos mais conhecidos, é apresentar abordagens que possibilitem reduzir a complexidade no processo de construção de cenários ao mesmo tempo em que mantém a robustez da análise e dos resultados.

Neste trabalho, uma pesquisa exploratória em que se utiliza o método hipotético-dedutivo com uma abordagem metodológica, os processos e as ferramentas contidos nas etapas de análise estrutural, análise morfológica e método de especialistas e probabilização são descritos de forma abrangente com o objetivo de propor duas diferentes abordagens inovadoras:

1. iniciar o processo com o preenchimento da matriz de impactos cruzados e extrair automaticamente desta uma análise estrutural. Dessa forma, obtêm-se, em apenas uma análise, duas informações importantes para o processo: a hierarquização das variáveis e o mapeamento do espaço probabilístico do conjunto de relações entre as variáveis;

2. desenvolver o conceito de redes bayesianas como critério de avaliação em uma análise morfológica para criar um subespaço morfológico quantificado, utilizando uma matriz de impactos cruzados probabilística para alimentação e tratamento dos dados.

Para a análise da efetividade dessas abordagens foram utilizados os seguintes critérios:

- as bases teóricas conferem confiabilidade e credibilidade ao método desenvolvido;

- o método não dá margens a interpretações, estando claros os objetivos e os papéis de cada etapa;

- $\quad$ há facilidade de realizar a retroalimentação no processo; 
- a quantidade de informações necessárias para alimentar as ferramentas é reduzida.

Esta pesquisa torna-se especialmente relevante porque, em relação ao método original de Michel Godet, propõe a redução da quantidade de informações necessárias para alimentar as ferramentas e maior integração das etapas do método, melhorando o processo de feedback. Gerencialmente, isso significa que os tomadores de decisão terão, com essa abordagem, um método que possibilita maior agilidade na análise e melhor visão holística do sistema, mantendo-se o nível de robustez da análise e credibilidade dos resultados. Cientificamente, são abordagens inovadoras que abrem um novo campo para estudos de cenários, já que se apropriam do conceito de redes bayesianas, muito utilizado em outras áreas do conhecimento (inteligência artificial, estudos geológicos, diagnósticos médicos, classificação de padrões, etc.), e o trazem para o campo das ciências sociais.

\section{REVISÃo BIBLIOGRÁFICA}

\subsection{MÉTODO DE CENÁRIOS}

Como já exposto anteriormente, entre os métodos mais celebrados, o que apresenta estrutura mais robusta, racionalista e menos dependente da intuição do usuário é o de Michel Godet. Em sua metodologia, Michel Godet (1993) integra o método de construção de cenários a duas tarefas: o diagnóstico da organização e o apoio às escolhas estratégicas. Para Michel Godet, os objetivos do Método de Cenários são três:

- $\quad$ identificação das variáveis-chave que caracterizam o sistema estudado, estabelecendo as relações entre elas mediante análise exaustiva;

- determinação dos atores fundamentais, de suas estratégias e dos meios de que dispõem para a realização de seus objetivos;

- descrição da evolução do sistema estudado levando em consideração as evoluções mais prováveis das variáveis-chave quando relacionadas entre si e influenciadas pelos jogos dos atores. 
O método de Godet (Figura 1) caracteriza-se por ser o mais robusto e dos menos flexíveis, pois acredita no rigor do uso das ferramentas de análise. É um dos poucos métodos que utilizam o conceito de probabilidades subjetivas para analisar os cenários desenvolvidos.

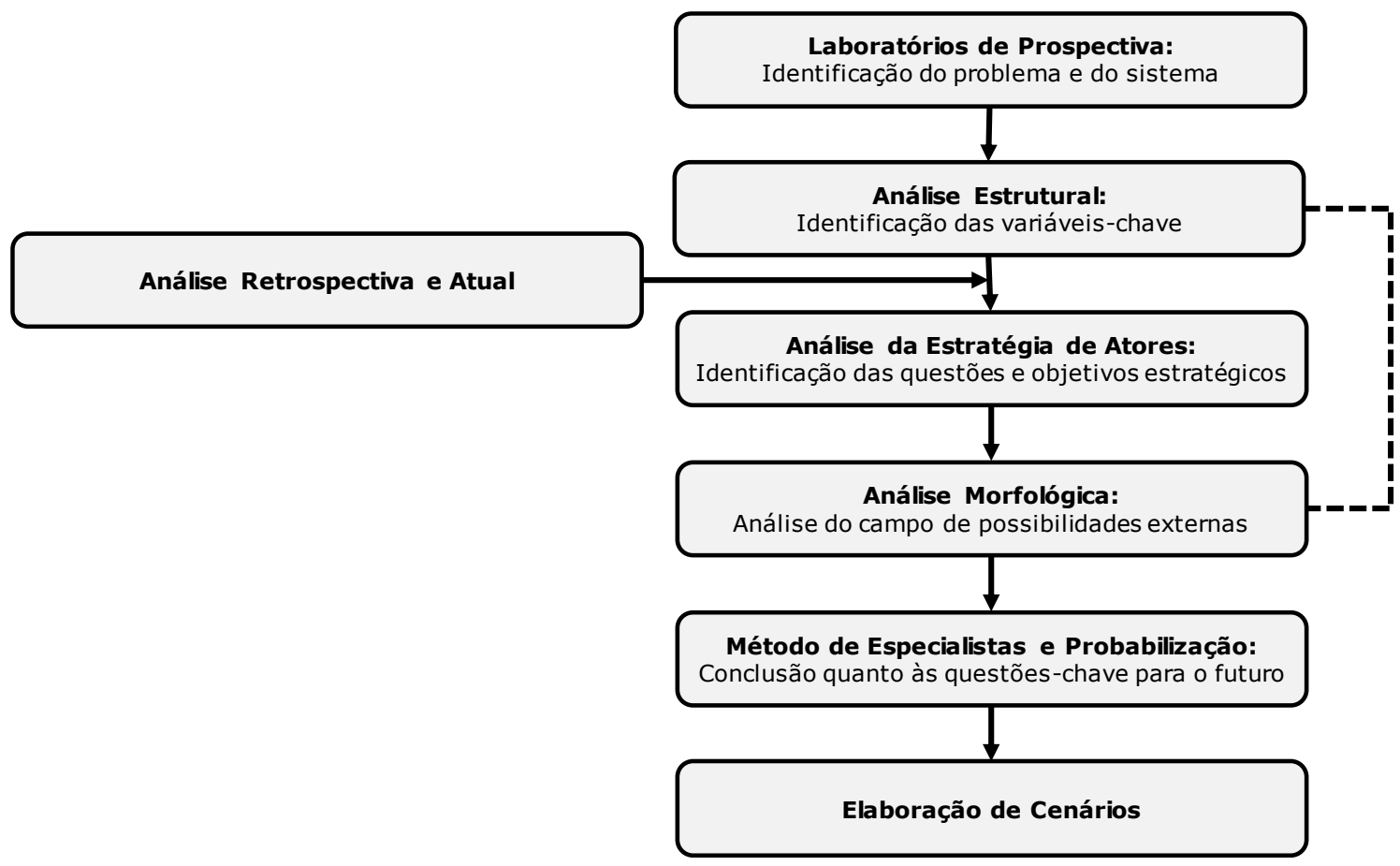

Figura 1: Método dos Cenários de Michel Godet

Fonte: Adaptado de Godet (1993)

A primeira etapa, em que ocorre a delimitação do sistema e do ambiente, serve para especificar a abrangência do estudo. Nela são definidos o objeto do estudo, o horizonte temporal e a área geográfica, ou seja, o foco do estudo. Geralmente parte-se de uma preocupação da empresa.

A segunda etapa inicia-se com a elaboração de uma lista completa das variáveis que de alguma forma possam explicar o comportamento do sistema constituído. Em seguida é realizada a análise estrutural (MICMAC), que permite a classificação das variáveis em relação a certo número de parâmetros fundamentais para caracterizar seu papel no sistema, pondo em evidência uma hierarquia de variáveis e facilitando a identificação das variáveis-chave.

Na etapa seguinte, são analisados os jogos de atores. O exame de suas relações de força é essencial para pôr em evidência qual é a evolução 
dos desafios estratégicos e para colocar as questões-chave para o futuro, já que os atores tenderão a manipular as variáveis de acordo com seus objetivos estratégicos. Esses atores e seus objetivos estratégicos são confrontados em suas convergências e divergências numa matriz chamada MACTOR, cuja saída é a identificação dos atores mais influentes nas variáveis do sistema.

$\mathrm{Na}$ etapa subsequente, é aplicada a análise morfológica e tem começo a exploração do campo das evoluções possíveis. Inicia-se o processo agrupando as variáveis-chave da análise estrutural. A seguir são definidas as restrições entre eventos para redução do espaço morfológico. Ao final, explora-se a combinatória dessas configurações utilizando as questões-chave do jogo de atores. No Método de Cenários, usa-se a ferramenta chamada Morphol.

A etapa seguinte trata da utilização de um método de impactos cruzados de caráter binário (ferramenta SMIC-Prob-Expert), na qual entra um número mais restrito de hipóteses centrais, já filtradas da análise morfológica. Essa fase baseia-se na consulta a um conjunto de peritos, para os quais são propostas questões a respeito das probabilidades simples (a priori) de um evento e das probabilidades condicionadas (a posteriori) de certo evento realizar-se em relação a algum outro. Em seguida, realiza-se uma análise de sensibilidade e robustez, que pode resultar em um feedback para o início do processo.

Na última etapa ocorre, finalmente, a elaboração dos cenários. Essa etapa é realizada em duas fases principais: aperfeiçoamento das imagens finais dos cenários no horizonte temporal do estudo e construção de uma narrativa que corresponda às imagens finais desenhadas.

\subsection{FERRAMENTAS DE CENÁRIOS}

\subsubsection{Análise estrutural}

A análise estrutural, segundo Arcade, Godet, Meunier e Roubelat (1994), é uma das ferramentas mais utilizadas nos estudos de futuro e tem dois objetivos complementares (Godet, 1993): durante a fase inicial, obter 
a melhor representação possível do sistema em estudo; e reduzir a complexidade do sistema pela escolha das variáveis principais.

A análise estrutural, instrumento de estruturação da reflexão coletiva, oferece a possibilidade de descrever um sistema com o auxílio de uma matriz que relaciona todos os elementos constituintes desse sistema (Godet, Monti, Meunier \& Roubelat, 1999). O objetivo desse método é fazer emergirem as principais variáveis influentes e dependentes, determinando assim as variáveis essenciais para a evolução do sistema. Tem como principais etapas: o recenseamento das variáveis, a descrição das relações entre as variáveis e a identificação das variáveis-chave.

$\mathrm{Na}$ primeira etapa, lista-se o conjunto das variáveis que caracterizam o sistema estudado. Nesta etapa convém ser o mais exaustivo possível e não excluir, a priori, nenhuma via de pesquisa. Nessa fase é desejável alimentar a recolha das variáveis por meio de entrevistas não diretivas com representantes de atores do sistema estudado. Obtém-se, finalmente, uma lista de variáveis internas e externas ao sistema considerado.

$\mathrm{Na}$ segunda etapa, procura-se identificar as relações existentes entre as variáveis utilizando uma matriz de análise estrutural. O preenchimento é qualitativo, sendo questionado para cada par de variáveis se há uma relação de influência direta da variável $i$ na variável $j$. Em resposta a essa questão, pode-se preencher essa matriz de duas formas: booleana (com 1 se há relação e 0 caso não ocorra) ou quantificando as relações (por exemplo, definindo as relações como: inexistente $=0$, fraca $=1$, média $=2$, forte $=3$ ). Na Figura 2, ilustra-se o processo de preenchimento de uma matriz booleana com dados gerados aleatoriamente.

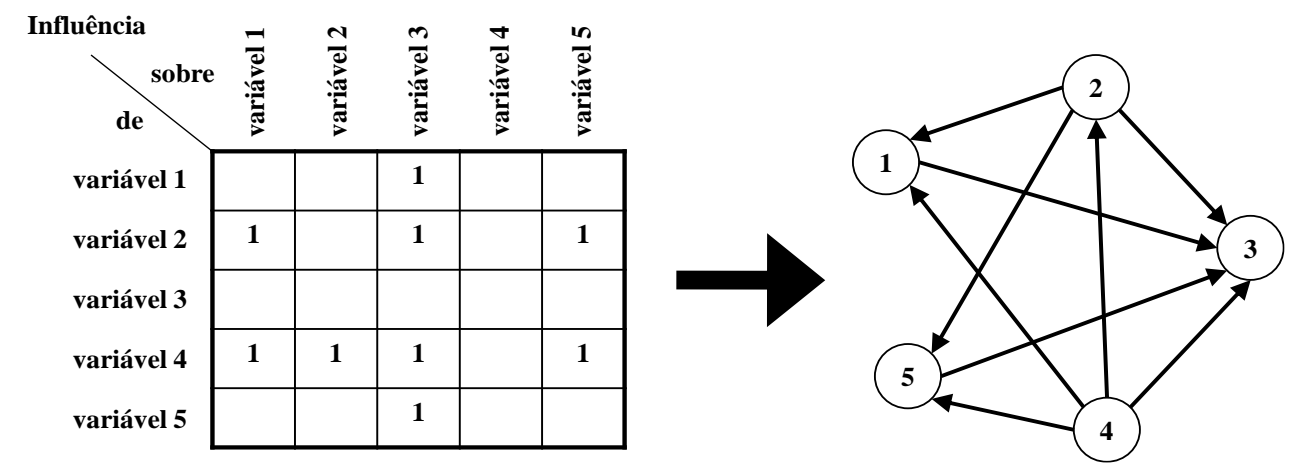

Figura 2: Matriz estrutural de relações diretas e grafo adjacente

Fonte: Arcade et al. (1994) 
Esta fase de preenchimento ajuda a colocar, para $n$ variáveis, $n .(n-$ 1) questões, algumas das quais teriam sido omitidas se não tivesse havido uma reflexão tão sistemática e exaustiva. O resultado visual da matriz estrutural é um grafo cujos nós (ou vértices) são as variáveis; e as arestas, suas inter-relações alimentadas na matriz de análise estrutural (Arcade et al., 1994).

Na próxima etapa, o grafo resultante da etapa anterior pode ser representado de forma a contribuir para decifrar as inter-relações do sistema e, se possível, hierarquizar as variáveis em sucessivos níveis de propagação de influências (Arcade et al., 1994), como se mostra na Figura 3.

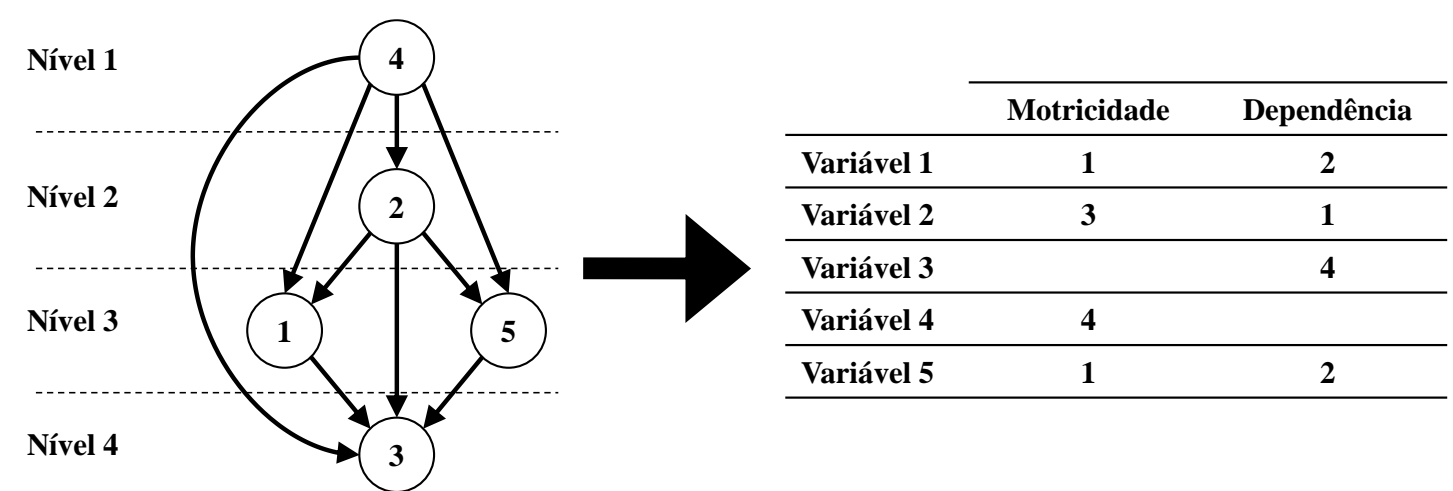

Figura 3: Grafo hierarquizado e suas motricidades/dependências

Fonte: Adaptado de Arcade et al. (1994)

Em uma abordagem bem intuitiva, a influência direta (motricidade) de uma variável pode ser apreciada considerando-se as linhas na matriz estrutural. Uma variável agindo em um menor número de variáveis exerce sua influência em uma parte limitada do sistema. Igualmente, a dependência direta de uma variável é obtida considerando as colunas da matriz, ou seja, a soma das influências diretas exercidas nessa variável. Portanto, somando sistematicamente os elementos de cada linha e coluna da matriz estrutural, é possível para cada variável ter a medida da motricidade e dependência para o sistema como um todo (Arcade et al., 1994).

No sistema utilizado como exemplo, é suficiente realizar a análise apenas tomando como informação suas relações diretas, já que o sistema é acíclico, ou seja, não apresenta circuitos. Porém, em análises mais extensas 
e complexas, é necessária a criação de algoritmos para, quando o sistema apresentar circuitos, considerar as relações indiretas entre as variáveis. 0 MICMAC, ferramenta do Método de Cenários de Godet, é o mais conhecido, mas apresenta algumas limitações (Perestrelo \& Caldas, 1998): indeterminação da motricidade e dependência indiretas, sobrevalorização da retroalimentação, ausência de estabilidade, efeitos multiplicativos, separação entre efeitos diretos e indiretos. Para resolver esses problemas do MICMAC, há métodos alternativos, como o Fluxo Máximo e a Propagação de Efeitos.

\subsubsection{Método de Impactos Cruzados}

Método de Impactos Cruzados é o nome genérico para uma família de técnicas que tentam avaliar as mudanças na probabilidade de ocorrência de determinado evento quando relacionado à ocorrência anterior de algum outro. O método começa com uma lista dos acontecimentos e suas probabilidades associadas. A hipótese básica do método é que muitas vezes nas probabilidades individuais já se consideram as interações entre eventos, mas apenas de forma incompleta. Ter em conta as interdependências permite passar de um sistema de probabilidades iniciais não processadas para um conjunto de probabilidades "líquidas", ou seja, corrigidas. O restante do método consiste em analisar a sensibilidade do sistema na construção de cenários, destacando as imagens finais mais prováveis (Godet, 1993).

Independentemente do tipo de abordagem, o Método de Impactos Cruzados tem uma base metodológica bem definida. É um método de abordagem analítica, aplicado às probabilidades de um item dentro de um sistema em previsão. Suas probabilidades podem ser ajustadas em virtude de decisões relativas a possíveis interações entre os itens. Sabe-se, por experiência, que a maior parte dos acontecimentos está, de alguma forma, relacionada com outros eventos. A partir desse fluxo interligado, os eventos correm cada vez mais amplamente enquanto interagem com outros eventos, formando uma grande rede de interconexões. É essa inter-relação entre eventos que é chamada de "impactos cruzados" (Gordon, 1994). 
O primeiro passo para uma análise de impactos cruzados é definir os eventos a serem incluídos no estudo. Esse primeiro passo pode ser crucial para o sucesso do exercício. Qualquer evento não incluído no sistema será, naturalmente, completamente excluído do estudo. No entanto, a inclusão de eventos não pertinentes pode complicar desnecessariamente a análise.

Após a definição do conjunto de eventos, o próximo passo é estimar a probabilidade inicial de cada evento, que indica como cada um deles poderá comportar-se por alguns anos futuros. Segue-se o próximo passo na análise, que é estimar as probabilidades condicionais de cada par de eventos. Tipicamente, os impactos são estimados em resposta à pergunta: "Se o evento $V_{j}$ ocorre, qual é a probabilidade de ocorrência do evento $V_{i}$ ?". Assim, se a probabilidade do evento $V_{i}$ foi originalmente julgada em $P\left(V_{i}\right)$, e se for considerado que $V_{j}$ ocorreu, uma nova probabilidade $P\left(V_{i} / V_{j}\right)$ poderá ser atribuída ao evento $V_{i}$. Toda matriz de impactos cruzados é preenchida colocando-se essa questão a cada par de eventos em relação à ocorrência e não ocorrência dos eventos (Figura 4).

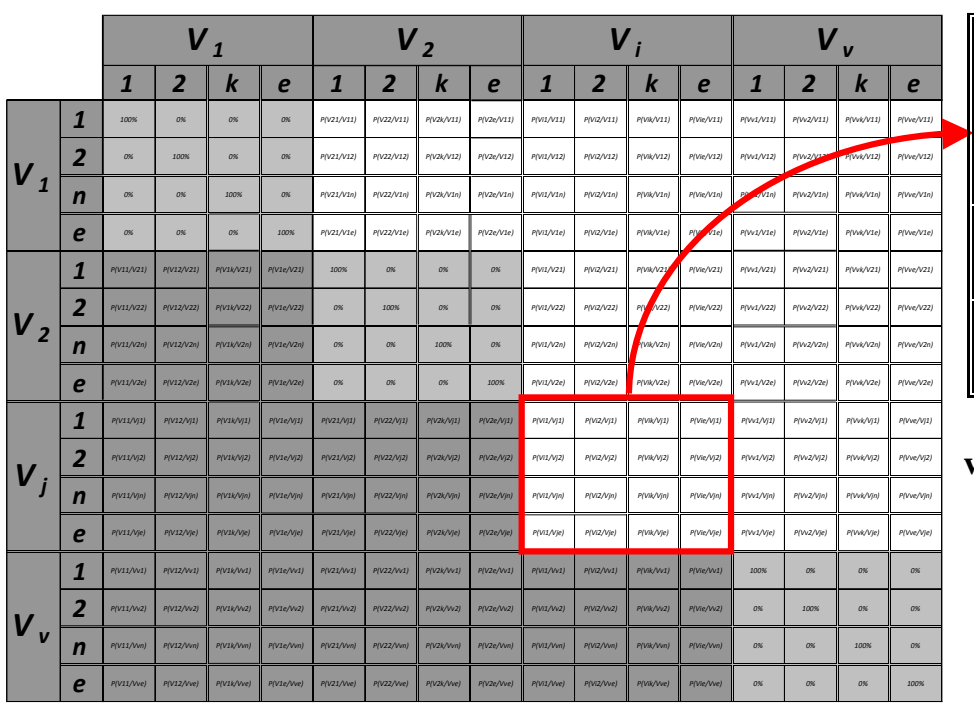

\begin{tabular}{||l|l||l||l||}
\hline \hline$P\left(V_{i 1} / V_{j 1}\right)$ & $P\left(V_{i 2} / V_{j 1}\right)$ & $P\left(V_{i k} / V_{j 1}\right)$ & $P\left(V_{i e} / V_{j 1}\right)$ \\
\hline$P\left(V_{i 1} / V_{j 2}\right)$ & $P\left(V_{i 2} / V_{j 2}\right)$ & $P\left(V_{i k} / V_{j 2}\right)$ & $P\left(V_{i e} / V_{j 2}\right)$ \\
\hline \hline$P\left(V_{i 1} / V_{j n}\right)$ & $P\left(V_{i 2} / V_{j n}\right)$ & $P\left(V_{i k} / V_{j n}\right)$ & $P\left(V_{i e} / V_{j n}\right)$ \\
\hline \hline$P\left(V_{i 1} / V_{j e}\right)$ & $P\left(V_{i 2} / V_{j e}\right)$ & $P\left(V_{i k} / V_{j e}\right)$ & $P\left(V_{i e} / V_{j e}\right)$ \\
\hline
\end{tabular}

Visualização do cruzamento de variáveis genéricas $V_{i}$ e $V_{j}$, sendo $i \neq j$

\section{Figura 4: Matriz de impactos cruzados genérica}

Fonte: Elaborado pelo autor

Quando as probabilidades iniciais são estimadas com referência aos outros eventos, algumas informações adicionais entram na estimativa do sistema. Para cada evento combinado, há limites para que as probabilidades condicionais possam existir (Gordon, 1994). A questão principal é que, mesmo que um perito possa responder com probabilidades condicionais 
simples para vários pares de eventos, é praticamente impossível que suas respostas atendam os clássicos axiomas que regem a Teoria das Probabilidades, como a regra da soma e a regra do produto (Godet, 1993).

A partir desse ponto, os resultados obtidos dependem dos processos e das fórmulas de transição adotadas para calcular a probabilidade final. É possível, por exemplo, que os participantes da análise decidam que um julgamento deve ser mudado, ao observar a dinâmica do sistema. Esse processo de aprendizagem, que ocorre enquanto a matriz de impactos cruzados está sendo estimada, é um dos principais benefícios da realização dessa abordagem (Gordon, 1994).

\subsubsection{Análise morfológica}

A análise morfológica (morphologycal analysis - MA), a mais antiga técnica de estruturação de incertezas para uso em cenários, nasceu e foi utilizada durante décadas primeiramente em áreas totalmente diversas da ciência. Segundo Ritchey (2002), desenvolver cenários futuros apresenta uma série de dificuldades metodológicas, como a de quantificar fatores que contêm fortes dimensões sociopolíticas e jogos entre atores. Nesse contexto, a análise morfológica mostra-se como uma alternativa para métodos matemáticos formais e de modelagem causal: uma forma de modelagem não quantificada, baseada em processos de julgamento e coerência interna. A modelagem causal pode ser utilizada como um auxílio ao julgamento.

MA é um título sofisticado para um método simples que se provou muito útil para estimular a imaginação, ajudando a identificar produtos e processos até então desconhecidos e a explorar o campo de possíveis cenários futuros (Godet, 1993). O princípio fundamental é a decomposição do sistema estudado em subsistemas ou componentes, que devem ser o mais independentes possível e cobrir a totalidade do sistema estudado. Isso forma o chamado espaço morfológico (Figura 5). 


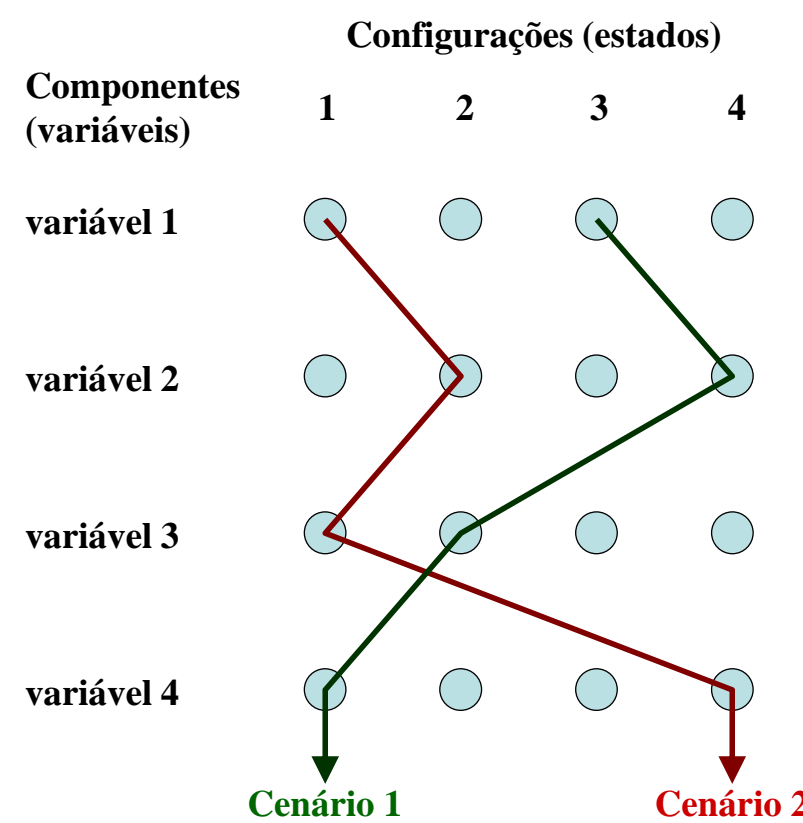

\section{Figura 5: Espaço morfológico}

Fonte: Elaborado pelo autor

Finalmente, o próximo passo no processo de análise-síntese é reduzir o conjunto de possíveis configurações totais de um espaço morfológico a um conjunto menor de configurações internamente consistentes representando um "espaço de solução", ou um subespaço morfológico.

\subsubsection{Redes bayesianas}

Os grafos já provaram ser uma linguagem muito intuitiva para representar estados de dependência e independência e, portanto, fornecem uma excelente forma de comunicar e discutir essas dependências e independências entre variáveis no domínio de um dado problema. De acordo com Pearl (2000), os papéis dos grafos em modelagem probabilística são: fornecer meios convenientes de expressar atribuições importantes, facilitar representações econômicas de funções de probabilidades conjuntas e facilitar inferências eficientes geradas por observações.

Por trabalhar tão bem com a visualização das dependências em um dado sistema de variáveis, o conceito de grafos é uma excelente ferramenta para representar redes causais. Conforme Kjærulff e Madsen (2005), o 
conceito de causalidade exerce um papel importante no processo de construção de modelos de redes probabilísticas. Para contextualizar causalidade, neste trabalho é utilizada a abordagem de pensamento causal (ou raciocínio causal, do inglês causal reasoning) e não "causação" (do inglês causation). Isso significa que a afirmação do modelo seria: "o evento $A$ causa com certeza $x$ o evento $B^{\prime \prime}$. Partindo disso, o pensamento causal seria: "se é conhecido que $A$ aconteceu, então $B$ pode acontecer com certeza $x^{\prime \prime}$.

As redes bayesianas (bayesian networks - BN) são um dos métodos de raciocínio em redes probabilísticas mais populares entre profissionais de Inteligência Artificial. Esse nome foi cunhado por Judea Pearl em 1985, mas as ideias e conceitos vieram de muitas fontes. Há variadas aplicações desse método (diagnóstico médico, mapas de aprendizado, entendimento da linguagem, visão em máquinas, busca heurística, etc.), mas, apesar da aparente importância, as ideias e técnicas não foram difundidas muito além das fronteiras da comunidade responsável por elas (Charniak, 1991).

No universo das $\mathrm{BN}$, o grafo que representa as relações causais entre as variáveis é o Grafo Direcionado Acíclico (Directed Acyclic Graph $D A G)$. Sua principal característica é a ausência de arcos que representem retroalimentação no modelo. O DAG é uma classe de grafos que pode representar de forma muito compacta um grande e importante conjunto de atribuições de relações de dependência e independência expressas em representações fatoradas de distribuições de probabilidades conjuntas (Kjærulff \& Madsen, 2005).

As BN oferecem uma abordagem para o raciocínio probabilístico que engloba, de um lado, a teoria dos grafos para o estabelecimento das relações causais entre sentenças (parte qualitativa) e, de outro, a teoria das probabilidades, para atribuição de níveis de confiabilidade (parte quantitativa). A melhor forma de entender BN é imaginar a modelagem de uma situação na qual a causalidade exerce papel importante, porém não há entendimento completo do que está acontecendo. Ou seja, a incerteza é inerente ao modelo e é necessário explicá-lo utilizando probabilidades. Pearl (2000) fornece três aspectos que devem ser enfatizados em BN: a natureza subjetiva das informações que alimentam o modelo; a confiança na regra 
de Bayes como base para atualização das informações; a distinção entre formas de raciocínio causal e "evidencial". Esses aspectos evidenciam que não apenas a construção de um modelo gráfico em uma rede bayesiana é qualitativa, mas também não necessariamente as probabilidades devem estar baseadas em frequências. Probabilidades também podem ser estimativas completamente subjetivas sobre a expectativa acerca de um evento. Isso de nenhuma forma invalida a utilização das regras de cálculo de probabilidades (Jensen, 1996).

Em BN, as relações causais entre as variáveis são expressas na forma de probabilidades condicionais. Ou seja, dado um evento $A$, tem-se uma probabilidade $P(A)$ de ocorrência. Porém, sabe-se que $A$ está condicionado à ocorrência de $B$, então a probabilidade de $A$ ocorrer, dado que $B$ ocorreu, é $P(A / B)$. Ou seja, a probabilidade de ocorrência de $A$ alterase ao se conhecer um novo dado. Dentro da teoria das probabilidades, o axioma mais importante para BN é a chamada regra fundamental, regra da multiplicação ou regra de Bayes: para dois eventos $A$ e $B$, a probabilidade de que ambos ocorram é $P(A \cap B)=P(A, B)=P(A / B) \cdot P(B)=P(B / A) \cdot P(A)$. Esse axioma explica que a probabilidade da ocorrência de dois eventos simultaneamente pode ser obtida multiplicando-se a probabilidade de ocorrência de um dos eventos pela probabilidade condicional de ocorrência do outro evento caso o primeiro aconteça. O resultado $P(A, B)$ é conhecido como Probabilidade Conjunta de $A$ e $B$.

O problema maior em redes causais reside no fato de haver muitas informações a serem tratadas. Por exemplo, um DAG completo que contenha $v$ variáveis, cada variável contendo e estados, terá $v \cdot e^{2} \cdot(v-1) / 2$ probabilidades condicionadas par a par e $e^{v}$ valores possíveis na distribuição das probabilidades conjuntas. Realizar uma inferência exata consiste em se conhecerem todos esses valores em uma rede bayesiana discreta. Também há vários métodos ( $\mathrm{p}$. ex.: Monte Carlo) para realização da chamada inferência aproximada, que deve ser utilizada quando há desconhecimento sobre várias variáveis no sistema estudado (Ben-Gal, 2007).

Há uma forma de simplificar os cálculos em uma rede bayesiana, reduzindo o número de informações a apenas informações relevantes, com base em como a informação se propaga na rede. Esse critério é chamado 
separação-d (d-separation) e define a relação de dependência ou independência de qualquer par de variáveis em uma rede causal, dado que uma nova evidência entrou na rede (Jensen, 1996). Umas das vantagens de redes bayesianas é que elas admitem separação-d: se $A$ e $B$ são dseparados quando uma evidência $\varepsilon$ entra, então $P(A / B, \varepsilon)=P(A / \varepsilon)$. Isso significa que é possível utilizar separação-d para encontrar independências condicionais.

Considerando o conceito de independência condicional, é possível expressar a distribuição das probabilidades conjuntas de uma rede bayesiana através da multiplicação das probabilidades condicionais das conexões convergentes e independentes existentes na rede. Por exemplo, para um DAG completo representando um sistema de quatro variáveis (Figura 6), a probabilidade conjunta seria $P\left(V_{1}, V_{2}, V_{3}, V_{4}\right)=$ $P\left(V_{1}\right) \cdot P\left(V_{2} / V_{1}\right) \cdot P\left(V_{3} / V_{2}, V_{1}\right) \cdot P\left(V_{4} / V_{3}, V_{2}, V_{1}\right)$.

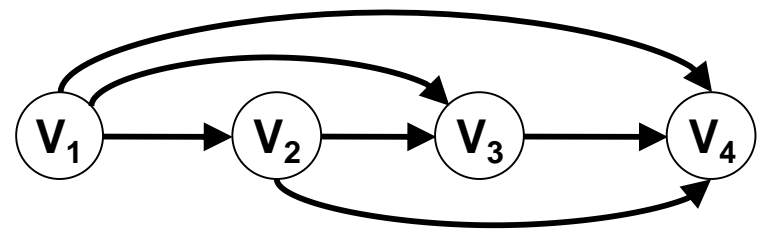

Figura 6: Representação gráfica de uma rede bayesiana de quatro variáveis

Fonte: Elaborada pelo autor

Generalizando para $n$, chega-se a:

$P\left(V_{1}, \ldots, V_{n}\right)=P\left(V_{n} / V_{n-1}, \ldots, V_{1}\right) \cdot P\left(V_{n-1} / V_{n-2}, \ldots, V_{1}\right) \ldots P\left(V_{2} / V_{1}\right) \cdot P\left(V_{1}\right)$

ou simplesmente:

$P\left(V_{1}, \ldots, V_{n}\right)=\prod_{i}^{n} P\left(V_{i} / P a\left(V_{i}\right)\right)$

Esse cálculo da probabilidade conjunta é chamado regra da cadeia, com $\mathrm{Pa}\left(V_{i}\right)$ representando os antecessores de $V_{i}$. Uma das questões em BN é como realizar a inferência probabilística para $P\left(V_{i} / P a\left(V_{i}\right)\right)$. Uma solução é simplesmente supor que as entradas são condicionalmente independentes entre si, simplificando a abordagem do problema sem comprometer significativamente a precisão do resultado (Lacerda \& Braga, 2004). Essa 
abordagem é conhecida como regra naïve de Bayes. Chama-se naïve (algo como ingênuo) justamente porque considera o conjunto $\left(V_{i-1}, \ldots, V_{1}\right)$ mutuamente independente dada a variável $V_{i}$. O Modelo Naïve de Bayes é uma forma especial da rede bayesiana muito usada em classificações e agrupamentos (clustering), mas pouco explorada em modelagem probabilística (Lowd \& Domingos, 2005). Desenvolvendo o conceito, partese de $P\left(V_{n} / P a\left(V_{n}\right)\right)=P\left(V_{n} / V_{n-1}, \ldots, V_{1}\right)$, aplica-se a regra de Bayes e considera-se que as variáveis são condicionalmente independentes:

$$
P\left(V_{n} / V_{n-1}, \ldots, V_{1}\right)=\frac{P\left(V_{n-1}, \ldots, V_{1} / V_{n}\right) . P\left(V_{n}\right)}{P\left(V_{n-1}, \ldots, V_{1}\right)}
$$

ou

$$
P\left(V_{n} / V_{n-1}, \ldots, V_{1}\right)=\frac{P\left(V_{n-1} / V_{n}\right) \ldots . P\left(V_{1} / V_{n}\right) \cdot P\left(V_{n}\right)}{P\left(V_{n-1}, \ldots, V_{1}\right)}
$$

ou simplesmente:

$$
P\left(V_{n} / V_{n-1}, \ldots, V_{1}\right)=\frac{P\left(V_{n}\right)}{P\left(P a\left(V_{n}\right)\right)} \cdot \prod_{j=1}^{n-1} P\left(V_{j} / V_{n}\right)
$$

Apesar de um tanto irrealista (por isso mesmo chamada naïve), essa suposição funciona notavelmente bem na prática. A naïve Bayes já provou sua efetividade em muitas aplicações práticas, incluindo classificação de texto, diagnóstico médico e gerenciamento do desempenho de sistemas (Rish, 2001).

De acordo com a regra naïve de Bayes mostrada acima, cada produto da regra da cadeia é fatorado a apenas probabilidades a priori e condicionais par a par. Ou seja, é possível calcular a probabilidade conjunta de uma rede bayesiana simplesmente condicionando probabilisticamente os pares de eventos (os arcos do DAG). Dessa forma, a regra da cadeia pode ser reescrita da seguinte forma, sendo que para $i=j, P\left(V_{j} / V_{i}\right)=1$ e para $V_{j}$ e $V_{i} \quad$ independentes, $P\left(V_{j} / V_{i}\right) \quad=\quad P\left(V_{j}\right)$ : $P\left(V_{1}, \ldots, V_{n}\right)=\prod_{i=1}^{n} \prod_{j=1}^{i} \frac{P\left(V_{i}\right)}{P\left(P a\left(V_{i}\right)\right)} . P\left(V_{j} / V_{i}\right)$ 


\section{APRESENTAÇÃO DAS PROPOSTAS}

A primeira etapa de qualquer modelagem causal é a escolha do conjunto de variáveis a ser estudado. Normalmente, o processo inicia-se na construção da estrutura do modelo utilizando-se a análise estrutural que, muito provavelmente, apresentará a forma de um grafo cíclico. A título de ilustração, para este trabalho foi construído um modelo booleano de quatro variáveis com valores gerados aletoriamente e cuja matriz de adjacência estrutural pode ser vista na Figura 7. Lembrando que uma das propriedades de redes causais é que as relações entre as variáveis podem ser consideradas transitivas, para ter-se uma melhor visão das relações indiretas entre as variáveis, foi aplicado um algoritmo de propagação de efeitos normatizado, que realiza o cálculo da junção dos efeitos diretos e indiretos das relações entre as variáveis do sistema. O resultado final desse processo é a construção de uma nova matriz de adjacência na qual as células recebem novos valores não booleanos representando suas relações diretas e indiretas. O próximo procedimento seria a hierarquização das variáveis pelos conceitos de motricidade e dependência.

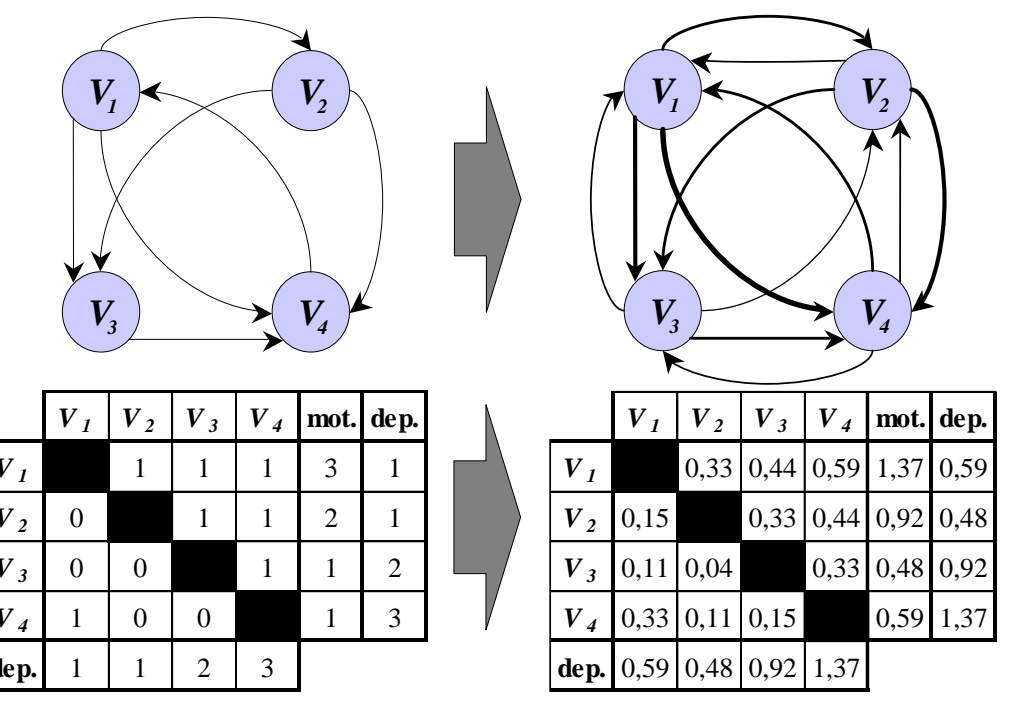

Figura 7: Análise estrutural com propagação de efeitos

\section{normatizado}

Fonte: Elaborada pelo autor 


\subsection{INTEGRAÇÃO DAS FASES DE ANÁLISE ESTRUTURAL E IMPACTOS} CRUZADOS

A primeira estratégia proposta neste artigo é justamente pular esse primeiro estágio de valoração dos arcos de um grafo apenas pela determinação de suas relações e ir direto ao preenchimento de uma matriz de impactos cruzados genérica (apresentada na Figura 4).

A partir desse momento, é possível calcular os valores de cada relação entre as variáveis do sistema ao interpretar-se que os valores da matriz de adjacência de uma análise estrutural são uma medida da influência que a variável antecessora realiza na variável condicionada. É possível afirmar isso a partir do momento em que se supõe logicamente que essa ordem de grandeza da influência é proporcional aos desvios entre as probabilidades a posteriori (condicionais) e as probabilidades a priori dos estados de uma variável. Ou seja, quanto maior é o valor do arco, mais influência a variável recebe de sua antecessora, maiores são os desvios entre as probabilidades a posteriori e a priori, mais dependente ela é de sua antecessora. Na lógica inversa, quanto menor é o valor do arco, menos influência ela recebe, menores são os desvios entre as probabilidades, mais independente ela é.

Tomando-se esse conceito de influência como o comportamento das probabilidades a posteriori, dada a probabilidade a priori e o valor do arco na matriz de adjacência, é proposta aqui a classificação das relações entre duas variáveis em quatro graus de influência:

- $\quad$ máxima influência: caracteriza a dependência total da variável sucessora em relação a sua antecessora, configurando uma relação de certeza causal. Ou seja, se o estado da variável antecessora é conhecido, então também já será conhecido o estado da sucessora. Em termos de probabilidades, isso significa que $P(A / B)=1$ e $P(A)=P(B)$;

- $\quad$ influência forte: caracteriza a forte influência da variável antecessora sobre a sucessora, isto é, as probabilidades condicionais $P(A / B)$, por influência da ocorrência de $B$, distanciam-se bastante de $P(A)$. Ou seja, há forte dependência da variável sucessora em relação à antecessora. No que concerne à ordem de grandeza, quanto mais próximo o 
valor na matriz de adjacência do valor de máxima influência, mais forte é essa influência;

- $\quad$ influência fraca: caracteriza a fraca dependência entre as variáveis e, portanto, uma fraca influência da variável antecessora sobre a sucessora. Isso quer dizer que as probabilidades a posteriori $P(A / B)$ estão relativamente próximas das probabilidades a priori $P(A)$. Quanto menor for o valor da relação entre essas variáveis, menor é essa influência e mais independentes elas são entre si;

- $\quad$ sem influência: caracteriza a independência entre as variáveis. Traduzindo-se em probabilidades, significa que $P(A / B)=P(A)$. O valor dessa relação é nulo.

Para ilustração desses conceitos, probabilidades genéricas foram geradas aleatoriamente e quatro conjuntos foram escolhidos como exemplos para cada um desses graus de influência citados anteriormente. Nesses exemplos (Figura 8), as tabelas de probabilidades consideram três estados (mutuamente exclusivos) para cada variável e suas probabilidades a priori e a posteriori. O cálculo dos valores dos graus de influência é realizado somando-se os valores absolutos das diferenças entre as probabilidades a posteriori e a priori, $[P(A / B)-P(A)]$, em cada estado de cada variável e depois normatizando-se pelo valor máximo possível de forma que esses valores fiquem limitados entre 0 e 1 . No caso de três estados por variável, esse valor máximo é 4 , que corresponde à soma de todos os elementos da matriz de valores absolutos apresentada na Figura 8. Genericamente, esse valor é dado pela fórmula 2.(e - 1), sendo e o número de estados de dada variável. 


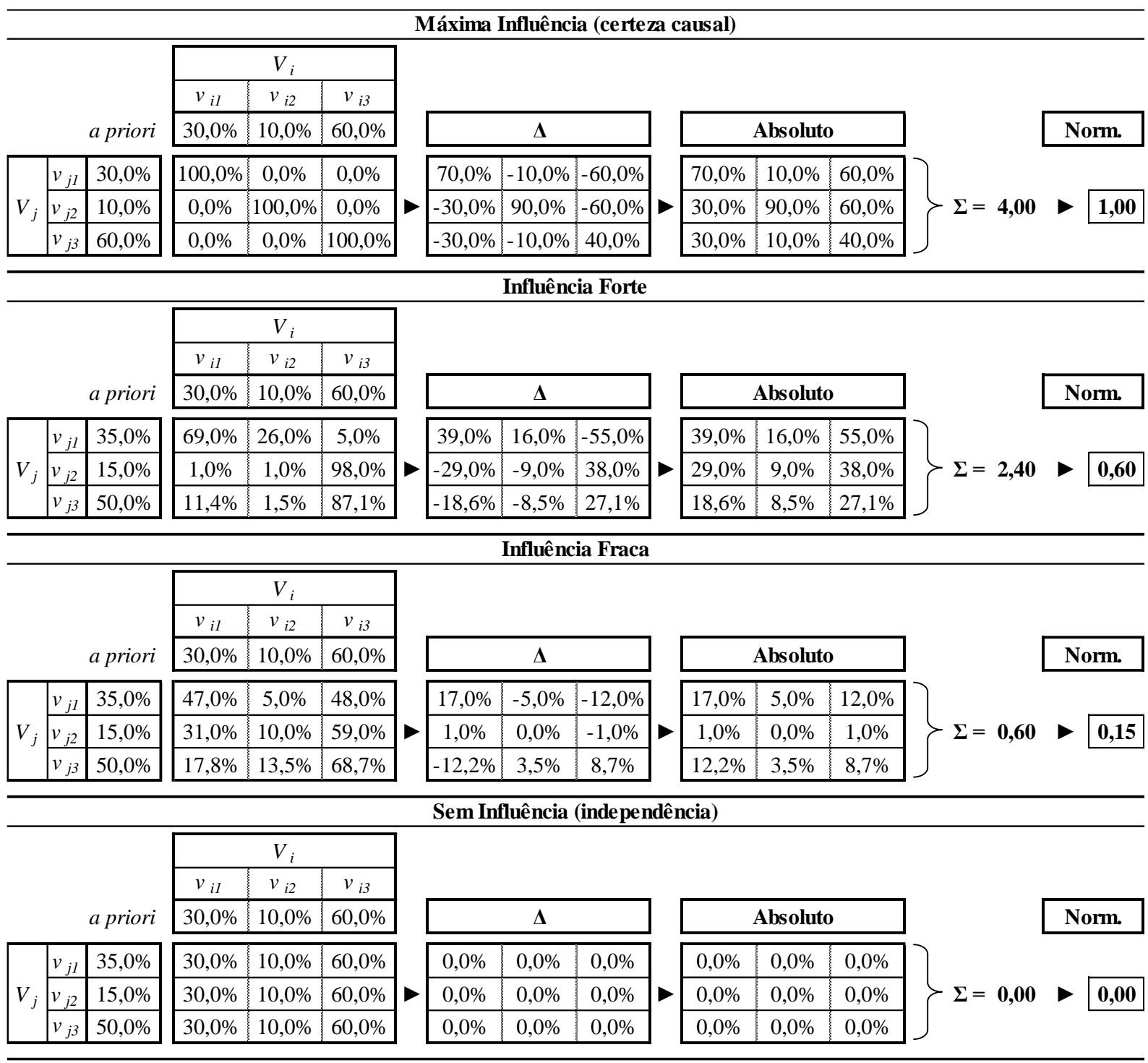

Figura 8: Desvios entre probabilidades como medida de dependência entre variáveis

Fonte: Elaborada pelo autor

O princípio que serve de base a esse método é a dedução lógica de que há uma correlação entre essas duas formas de mensurar o nível de dependência (ou influência) entre duas variáveis em um modelo causal:

- cálculo da junção das relações diretas e indiretas gerado pela análise de propagação de efeitos normatizado a partir de uma matriz booleana;

- normatização da soma dos valores absolutos dos desvios entre probabilidades a posteriori e a priori de todos os estados mutuamente exclusivos das variáveis. 
Para comprovar que a perda de informações é minimizada quando a estrutura de um modelo cíclico é simplificada para um DAG ao se desconsiderarem as relações de menor grau de influência, Fischer (2010) realizou um teste empírico que apresentou resultados bastante satisfatórios.

Quanto ao modelo construído, bastariam as informações contidas na matriz de impactos cruzados para obter as probabilidades de todas as configurações de variáveis que um modelo pode apresentar. Mas um dos papéis mais importantes do processo de construção de cenários é promover a experimentação e vivência dos usuários na dinâmica das relações entre as variáveis. A matriz morfológica possibilita tal experiência, já que, conforme os estados das variáveis vão sendo escolhidos, as probabilidades de cada nível vão emergindo, guiando o usuário na escolha da configuração desejada, porque os dados tratados dentro da matriz de impactos cruzados forma uma distribuição de probabilidades conjuntas que, aplicada na estrutura da análise morfológica, acaba criando um subespaço morfológico.

\subsection{REDES BAYESIANAS COMO BASE PARA O SUBESPAÇO MORFOLÓGICO}

Na segunda abordagem deste trabalho, é desenvolvida a utilização do conceito de redes bayesianas como forma de unificação da matriz de impactos cruzados e da análise morfológica, conforme Ritchey (2005) já havia proposto.

O conceito de redes bayesianas entra nesse quadro como um método de cálculo dos dados fornecidos através da consulta a especialistas na forma de probabilidades condicionais subjetivas acerca da ocorrência dos eventos envolvidos na construção dos cenários. O papel da matriz de impactos cruzados é ser utilizada como a tabela de probabilidades do modelo probabilístico, servindo como ferramenta pela qual as probabilidades são alimentadas, organizadas, verificadas quanto a sua consistência e preparadas para a etapa seguinte. A próxima etapa consiste na construção dos cenários propriamente ditos, na qual a ferramenta utilizada é a análise morfológica, que recebe as informações tratadas na Matriz de Impactos Cruzados pelos princípios de redes bayesianas, e as transforma em seu subespaço morfológico. 


\subsubsection{Estabelecimento da estrutura do modelo}

Já se sabe que a primeira etapa do processo de cenarização é a realização da análise estrutural, que geralmente resulta em um sistema cíclico. Como BN requerem sistemas causais acíclicos, o sistema cíclico resultante da análise estrutural necessita ser simplificado. Há várias formas de realizar essa simplificação; uma dessas estratégias é simplesmente transformar o grafo cíclico em um DAG ao remover ou adicionar algumas arestas até que todos os ciclos sejam quebrados. As arestas devem ser removidas ou adicionadas de modo que a diferença nos resultados obtidos na comparação entre os modelos seja minimizada e que nenhuma das dependências de dados no grafo cíclico seja violada (Sandnes \& Sinnen, 2004). Essa estratégia é suportada pelo conceito de estabilidade (Pearl, 1999) e pelos conceitos de dependência induzida e dependência normal (Pearl, 1988). Operacionalmente, para a realização dessa etapa, podem-se raciocinar os arcos de um grafo como vetores, processo sintetizado na Figura 9, em que se complementa o processo iniciado na Figura 7.

\section{Dígrafo Cíclico}

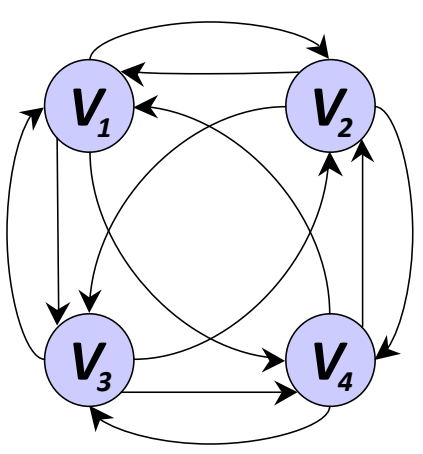

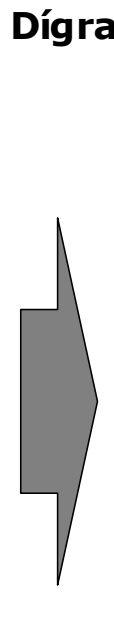

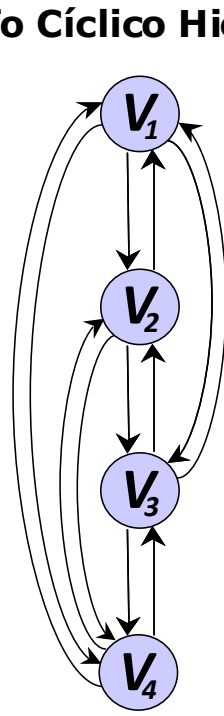

\begin{tabular}{|c|c|c|c|c|c|c|}
\cline { 2 - 7 } \multicolumn{1}{c|}{} & V1 & V2 & V3 & V4 & mot. & dep. \\
\hline V1 & & 0,33 & 0,44 & 0,59 & 1,37 & 0,59 \\
\hline V2 & 0,15 & & 0,33 & 0,44 & 0,92 & 0,48 \\
\hline V3 & 0,11 & 0,04 & & 0,33 & 0,48 & 0,92 \\
\hline V4 & 0,33 & 0,11 & 0,15 & & 0,59 & 1,37 \\
\hline dep. & 0,59 & 0,48 & 0,92 & 1,37 & \multicolumn{3}{c}{} \\
\cline { 1 - 5 } & & &
\end{tabular}

DAG
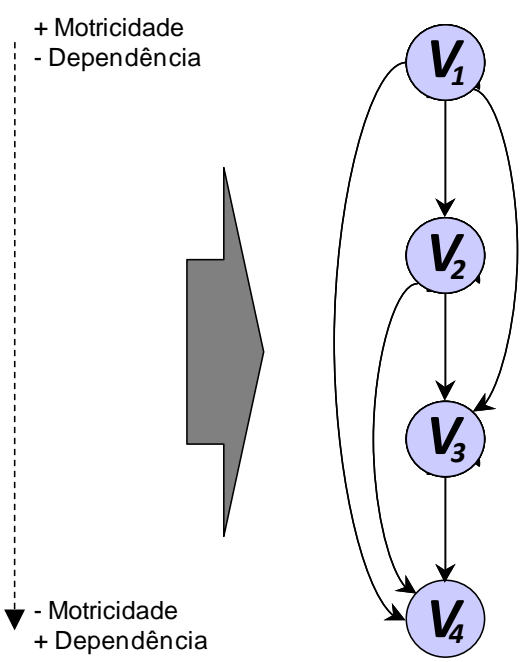

\begin{tabular}{|c|c|c|c|c|c|c|}
\cline { 2 - 8 } \multicolumn{1}{c|}{} & V1 & V2 & V3 & V4 & mot. & dep. \\
\hline V1 & & 0,19 & 0,33 & 0,26 & 0,78 & 0,00 \\
\hline V2 & 0,00 & & 0,30 & 0,33 & 0,63 & 0,19 \\
\hline V3 & 0,00 & 0,00 & & 0,19 & 0,19 & 0,63 \\
\hline V4 & 0,00 & 0,00 & 0,00 & & 0,00 & 0,78 \\
\hline dep. & 0,00 & 0,19 & 0,63 & 0,78 & \multicolumn{3}{c}{} \\
\hline
\end{tabular}

Figura 9: Redução para um DAG pela dependência normal

Fonte: Elaborada pelo autor 
Considerando-se um par de variáveis, estruturalmente (no caso de uma modelagem causal) ele pode conter no máximo dois arcos, cada um em um sentido. Se esses arcos são valorados, é possível assumir que são "vetores causais"; um deles tem o sinal positivo (direção da hierarquização realizada) e o outro, um sinal negativo (direção contrária). A junção desses dois "vetores" em sentidos opostos forma um vetor resultante em apenas uma direção (na direção do maior valor absoluto) e cujo valor é igual à diferença entre os valores absolutos de cada vetor. Ao se repetir esse processo para cada par de variáveis do modelo, é possível obter finalmente um DAG partindo de um dígrafo cíclico.

\subsubsection{Redes bayesianas como base para a matriz de impactos cruzados}

Na próxima etapa, é iniciada a fase quantitativa, em que as relações causais entre as variáveis receberão valores correspondentes às probabilidades de ocorrência de cada um de seus estados, lembrando que cada variável $V_{i}$ pode apresentar e estados mutuamente exclusivos $\left(v_{i 1}, v_{i 2}\right.$, $\left.\ldots, V_{i e}\right)$. É importante lembrar que essas probabilidades podem ter várias fontes: frequências já conhecidas, frequências inferidas, opinião do usuário do processo, opinião de especialistas, etc. Como o foco deste trabalho é a construção de cenários, as probabilidades são consultadas a especialistas que decidem se utilizarão frequências ou sua intuição ao conferir probabilidades aos eventos (ou seja, probabilidades subjetivas).

Retomando a representação gráfica de uma rede bayesiana apresentada na Figura 6 e relembrando a regra naïve de Bayes, para definir as relações em uma rede bayesiana, é necessário conferir apenas probabilidades a posteriori par a par para cada estado de cada variável do modelo. Com essas informações, é possível iniciar a alimentação da matriz de impactos cruzados genérica, já apresentada na Figura 4. Nesse momento, é possível perceber uma das grandes vantagens do uso de redes bayesianas em cenários. Sabendo-se que as variáveis já estão em ordem hierárquica na matriz, é fácil perceber que apenas a diagonal superior direita (parte clara da matriz da Figura 4) tem a necessidade de ser preenchida. Isso significa uma redução aproximada de metade do número de informações que seriam normalmente necessárias em outros métodos de 
impactos cruzados tradicionais - a quantidade total de informações (probabilidades a priori e a posteriori) numa matriz de impactos cruzados pode ser facilmente deduzida na fórmula $v . e .[e .(v-1)+1]$, em que $v$ é o número de variáveis do sistema e e é o número de estados de cada variável.

Porém, com as informações alimentadas na matriz de impactos cruzados, não é possível calcular os resultados das probabilidades conjuntas diretamente com a fórmula da regra da cadeia. Pela Figura 10, é fácil constatar que (a) representa as informações contidas na diagonal superior direita da matriz e as informações de (b) estão contidas na diagonal inferior esquerda (parte mais escura). Essa região da matriz de impactos cruzados seria automaticamente preenchida pela regra de Bayes a partir das informações contidas na diagonal superior direita da matriz.

(a)

(b)
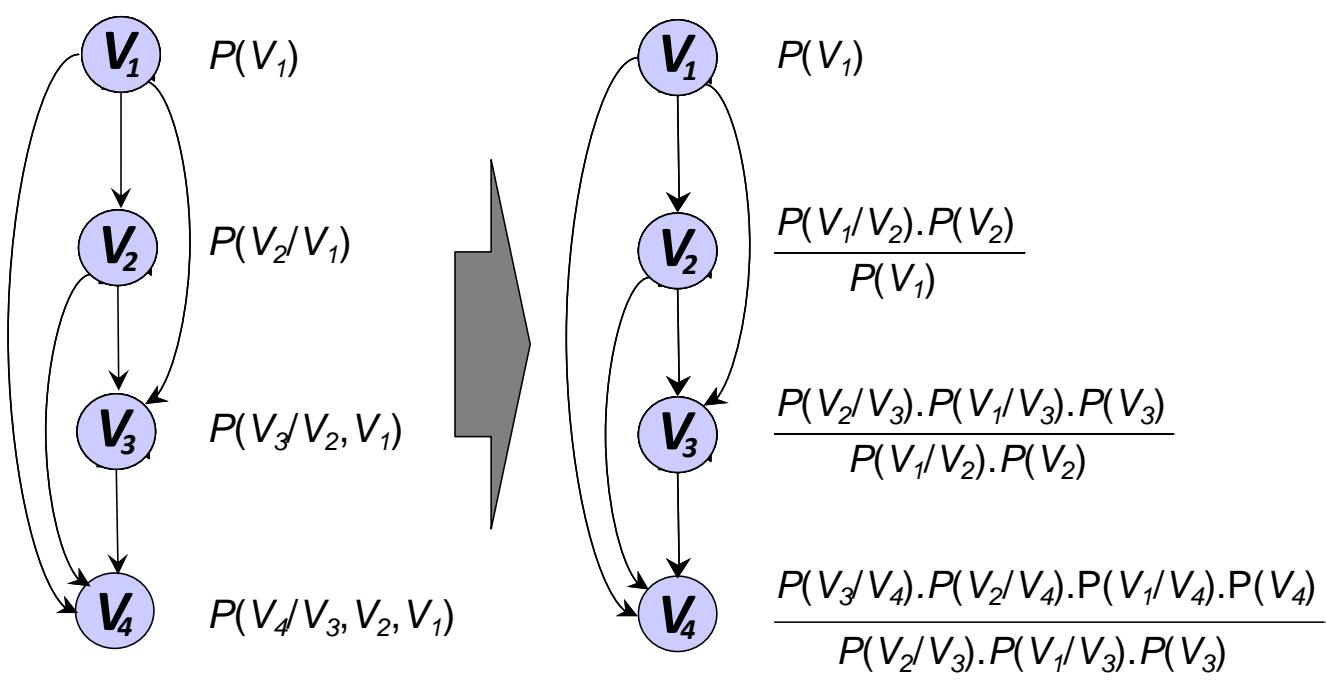

\section{Figura 10: Representação gráfica da regra da cadeia para um modelo de quatro variáveis}

Fonte: Elaborada pelo autor

Com as informações construídas na diagonal inferior esquerda da matriz de impactos cruzados, é possível agora o cálculo da distribuição das probabilidades conjuntas do modelo, contendo as probabilidades de todas as configurações de estados das variáveis. É sempre importante lembrar que, para toda análise de impactos cruzados utilizando-se o raciocínio probabilístico (independente da metodologia de cálculo utilizada), é 
necessário coerência e consistência entre as probabilidades atribuídas aos eventos, respeitando-se os axiomas da Teoria das Probabilidades.

E, finalmente, é chegado o estágio de configuração e vivência na construção dos cenários: a análise morfológica. Sendo a MA uma ferramenta hierarquizada, o conceito de BN encaixa-se perfeitamente na criação um subespaço morfológico, conforme pode ser visualizado na Figura 11.

\section{DAG}

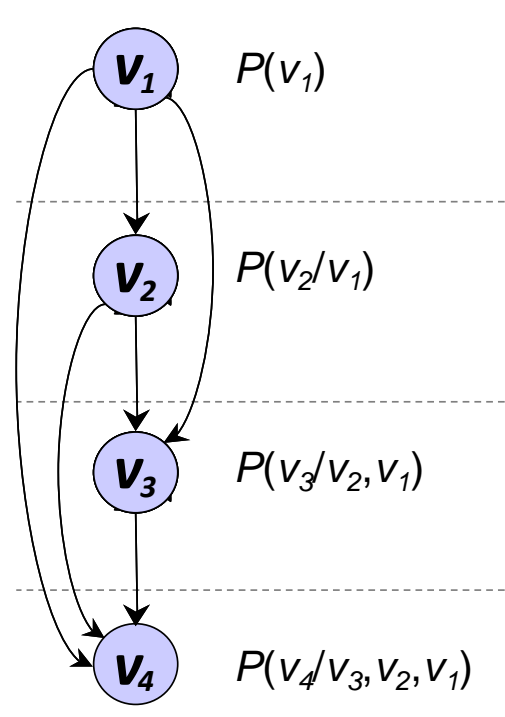

Espaço Morfológico

\begin{tabular}{|c|c|c|c|}
\hline \multicolumn{4}{|c|}{$v_{1}$} \\
\hline $\boldsymbol{V}_{11}$ & $V_{12}$ & $\ldots$ & $V_{1 e}$ \\
\hline \multicolumn{4}{|c|}{$v_{2}$} \\
\hline$V_{21}$ & $V_{22}$ & .. & $V_{2 e}$ \\
\hline \multicolumn{4}{|c|}{$v_{3}$} \\
\hline$V_{31}$ & $V_{32}$ & $\ldots$ & $V_{3 e}$ \\
\hline \multicolumn{4}{|c|}{$v_{4}$} \\
\hline$V_{41}$ & $V_{42}$ & & $V_{4 e}$ \\
\hline
\end{tabular}

$P\left(v_{1}\right)$

$\frac{P\left(v_{1} / v_{2}\right) \cdot P\left(v_{2}\right)}{P\left(v_{1}\right)}$

$\frac{P\left(v_{2} / v_{3}\right) \cdot P\left(v_{1} / v_{3}\right) \cdot P\left(v_{3}\right)}{P\left(v_{1} / v_{2}\right) \cdot P\left(v_{2}\right)}$

$\frac{P\left(v_{3} / v_{4}\right) \cdot P\left(v_{2} / v_{4}\right) \cdot P\left(v_{1} / v_{4}\right) \cdot P\left(v_{4}\right)}{P\left(v_{2} / v_{3}\right) \cdot P\left(v_{1} / v_{3}\right) \cdot P\left(v_{3}\right)}$

Figura 11: Estrutura de rede bayesiana como subespaço

\section{morfológico}

Fonte: Elaborada pelo autor

\section{CONSIDERAÇÕES FINAIS}

Em análises prospectivas, as ferramentas e métodos utilizados devem lidar com o mínimo de informações possível e ser simples o bastante para que os resultados possam ser facilmente assimilados pelos tomadores de decisões. Ao mesmo tempo, devem conferir robustez e credibilidade aos resultados alcançados.

Com base nas premissas acima, as propostas deste trabalho foram desenvolvidas visando ao objetivo de reduzir a complexidade no processo de construção de cenários, ao mesmo tempo em que se mantém a robustez 
da análise e dos resultados. De acordo com os critérios já expostos na seção Introdução, para a verificação dos conceitos de complexidade e robustez no contexto deste trabalho, de forma geral, a conclusão é que o método proposto, além de trazer a vantagem da redução da complexidade da análise, mostrou-se robusto, coerente, confiável e rigoroso, já que é suportado por bases teóricas consagradas. O Método de Cenários, de Michel Godet, já propõe a prática dessas ferramentas de forma complementar, mas não integrada. Isso porque são ferramentas de naturezas diversas:

- a análise estrutural é uma ferramenta que tem como objetivo principal justamente estudar e mapear a dinâmica entre as variáveis e determinar o grau de influência de cada uma no sistema. Sua limitação reside no fato de que esse grau de influência é sempre medido de forma muito subjetiva, não levando em consideração os estados possíveis que essa variável pode apresentar;

- a matriz de impactos cruzados é uma ferramenta quantificada que recebe e trata informações, verifica sua consistência e coerência e retorna os resultados. Porém, tem a deficiência de ser difícil visualizar as características do modelo, entender os padrões existentes e compreender a dinâmica nas relações entre as variáveis;

- a análise morfológica é uma ferramenta qualitativa que tem como características principais a fácil visualização do comportamento do modelo e a possibilidade de o usuário vivenciar a construção dos cenários e entender os padrões e dinâmicas existentes. Sua limitação reside no fato de muitas vezes a construção dos cenários estar baseada em regras subjetivas, o que pode gerar muita discussão e desconfiança.

Trabalhar na integração dessas ferramentas possibilita reduzir suas limitações enquanto maximiza suas vantagens. Uma dessas vantagens diz respeito a um dos papéis mais importantes do processo de construção de cenários - a experimentação e a vivência dos usuários do processo na dinâmica das relações entre as variáveis. É nesse aspecto que a integração permite ganho de eficiência, mas não pode desvirtuar os objetivos individuais de cada ferramenta. É importante, pois, que o usuário não 
receba simplesmente os resultados dos cenários, mas que vivencie e entenda a dinâmica entre as variáveis.

Além do fato de facilitar a navegação entre as ferramentas, a integração ainda facilita muito a retroalimentação do processo, possibilitando uma revisão na estrutura do modelo ou dados de entrada (probabilidades) e a visualização dos pontos de ruptura dentro do modelo. Esse feedback no processo, sendo possível retornar ao início da modelagem e modificar suas probabilidades de ocorrência a priori e a posteriori, é realizado caso seja percebido que:

- não parece haver muita coerência na dinâmica entre as variáveis. Nesse caso, a equipe de cenários deve estar muito atenta à condução do exercício para realizar a correta arbitragem evitando, assim, que esse processo de feedback leve à desconstrução das rupturas e retorno aos cenários normativos;

- o plano de ação desenvolvido no final do processo de "cenarização" tem impacto direto no sistema de variáveis e atores, modificando a estrutura do sistema (objetivo principal da Prospectiva Estratégica).

Ainda no tema complexidade, no caso do método de impactos cruzados, quanto mais rico em informações fica o sistema, mais complexo e longo se torna o processo. Isso porque a quantidade de informações necessárias para alimentar uma matriz de impactos cruzados cresce exponencialmente em relação ao aumento das variáveis que entram no modelo. Nesse ponto, existem dois ganhos. O primeiro é a proposta de suprimir a etapa de análise estrutural e utilizar a matriz de impactos cruzados para realizar diretamente a hierarquização das variáveis. O segundo é a utilização do conceito de redes bayesianas como forma de integrar o método de impactos cruzados à análise morfológica. Nesse último caso, número de informações, no caso, probabilidades, é reduzido praticamente pela metade. Ou seja, o modelo torna-se mais fácil de ser construído, tomando menos tempo e possibilitando maior agilidade na condução do processo. Como exemplo, um sistema de 16 variáveis ( $v$ ) com dois estados cada (e) teria a necessidade de ser alimentado com 992 informações de probabilidades (a priori e a posteriori) para completar uma matriz de impactos cruzados, dada a fórmula apresentada anteriormente, 
v.e.[e. $(v-1)+1]$. Utilizando-se redes bayesianas, esse número se reduz para 512, pois a fórmula para cálculo do número de informações evolui para v.e. $[0,5 \cdot e \cdot(v-1)+1]$.

No campo da busca pela robustez, pode-se concluir que há ganho direto no uso de redes bayesianas quando se verifica a necessidade de introdução de novas variáveis no sistema ou maior detalhamento dos estados das variáveis. Utilizando-se BN, é possível fazer isso sem elevação da complexidade. Tomando novamente o exemplo do parágrafo anterior, se for mantido o número de informações na mesma ordem de grandeza, é possível ter 22 variáveis em vez de 16 (968 probabilidades) ou reduzir o modelo para 15 variáveis, porém considerando três estados por variável (990 probabilidades). No caso da proposta deste trabalho, que faz uso da MA de forma integrada, quanto mais estratificada em estados é a variável, melhor. Portanto, a abordagem de enriquecimento do modelo por meio do aumento do número de estados das variáveis faz mais sentido (simplesmente não é possível desenvolver uma análise morfológica minimamente rica com dois estados por variável).

Uma das bases do desenvolvimento da proposta de utilização de redes bayesianas é a crença na confiabilidade das informações geradas pela consulta aos especialistas, o que constitui uma limitação da abordagem proposta. Os dados coletados podem ter diferentes níveis de confiabilidade, mas são tratados de forma idêntica. Além disso, conforme se apresentou no decorrer deste trabalho, não há como afirmar que probabilidades subjetivas a posteriori sejam mais confiáveis do que as probabilidades a priori. Uma forma de solucionar essa limitação é considerar que os especialistas já têm em sua mente todo o encadeamento de eventos ao estimarem as probabilidades a priori, que podem ser tratadas diretamente por métodos que utilizam, por exemplo, a distribuição Beta. A comparação entre essas duas abordagens para tratamento de opiniões (na forma de probabilidades) coletadas de especialistas pode configurar-se como uma pista para trabalhos futuros.

Outra limitação presente neste trabalho, agora na abordagem proposta de integração da análise estrutural com impactos cruzados, é a suposição de que há uma correlação entre os graus de influência das 
variáveis calculados através da análise estrutural e através dos desvios entre as probabilidades a priori e a posteriori dos estados das variáveis, indicando que essa valorização representa o nível de dependência entre as variáveis (quanto maior, mais dependente; quanto menor, mais independente). Essa afirmação é conceitual e parte apenas da dedução lógica, sem nenhuma confirmação empírica - a análise estrutural parte de valores nulos para definir independência, assim como o desvio nulo entre probabilidades a priori e a posteriori indica independência. Pode residir nesse fato outra uma pista para trabalhos futuros.

Por último, afirmou-se no decorrer deste trabalho, que a abordagem proposta reduz a complexidade da análise, mantém a robustez e permite aos usuários a fácil compreensão da metodologia e entendimento da dinâmica dos cenários. Essas afirmações foram feitas com base na crença de que a integração dessas ferramentas levaria o usuário de cenários a essas conclusões. Portanto, outra pista para trabalhos futuros seria medir a percepção de profissionais que trabalham com cenários sobre como se comporta a abordagem proposta em termos de complexidade da análise, robustez do processo, confiabilidade do resultado e entendimento da metodologia. 


\section{REFERÊNCIAS}

Arcade, J., Godet, M., Meunier, F., \& Roubelat, F. (1994). Structural analysis with the MICMAC method \& actors' strategy with MACTOR method. In J. C. Glenn, \& T. J. Gordon (Orgs.), Futures research methodology. Paris: AC/UNU Millennium Project.

Ben-Gal, I. (2007). Bayesian networks. In F. Ruggeri, R. S. Kennett, \& F. W. Faltin (Orgs.), Encyclopaedia of statistics in quality and reliability. UK: John Wiley \& Sons.

Charniak, E. (1991). Bayesian networks without tears. AI Magazine, 12(4), 50-63.

Duncan, N. E., \& Wack, P. (1994). Scenarios designed to improve decision making. Planning Review, 22(4), 18-46.

Fischer, R. B. (2010). Desenvolvendo o conceito de redes bayesianas na construção de cenários prospectivos. Dissertação de Mestrado, Escola Brasileira de Administração Pública e de Empresas da Fundação Getulio Vargas (EBAPE/FGV), Rio de Janeiro, RJ, Brasil.

Godet, M. (1993). From anticipation to action: a handbook of strategic prospective. Paris: UNESCO.

Godet, M., \& Roubelat, F. (1996). Creating the future: the use and misuse of scenarios. Long Range Planning, 29(2), 164-171.

Godet, M., Monti, R., Meunier, F., \& Roubelat, F. (1999). A caixa de ferramentas da prospectiva estratégica. Lisboa: CEPES.

Gordon, T. J. (1994). Cross impact method. In J. C. Glenn, \& T. J. Gordon (Orgs.), Futures research methodology. Paris: AC/UNU Millennium Project.

Heijden, K. (2004). Planejamento de cenários: a arte da conversação estratégica. Porto Alegre: Bookman.

Jensen, F. (1996). An introduction to Bayesian networks. London: UCL Press.

Kjærulff, U. B., \& Madsen, A. L. (2005). Probabilistic networks: an introduction to Bayesian networks and influence diagrams. Recuperado em 30 de junho, 2009, de http://www.cs.aau.dk/ uk/papers/pgm-bookI-05.pdf 
Lacerda, W. S., \& Braga, A. P. (2004). Experimento de um classificador de padrões baseado na regra naïve de Bayes. INFOCOMP Journal of Computer Science, 3(1), 30-35.

Lowd, D., \& Domingos, P. (2005). Naïve Bayes models for probability estimation. Proceedings of the International Conference on Machine Learning, 22, Bonn, Germany.

Marcial, E. C., \& Grumbach, R. S. (2005). Cenários prospectivos: como construir um futuro melhor (3a ed.). Rio de Janeiro: FGV.

Marques, E. (1988). Prospec: modelo de geração de cenários em planejamento estratégico. Recuperado em 11 de abril, 2007, de http://www.bndes.gov.br/conhecimento/livro_ideias/livro-11.pdf

Miles, I. (2005). Scenario planning. In UNIDO Technology foresight manual (vol. 1, pp. 168-193) Vienna: Unido.

Pearl, J. (1988). Probabilistic reasoning in intelligent systems: network of plausible inference. San Francisco, CA: Morgan Kaufmann.

Pearl, J. (1999). Graphs, structural models and causality. In C. Glymour, \& G. F. Cooper (Orgs.), Computation, causation and discovery. Cambridge, MA: AAAI/MIT Press.

Pearl, J. (2000). Causality: models, reasoning, and inference. New York, NY: Cambridge University Press.

Perestrelo, M. M. M. C., \& Caldas, J. M. C. (1998). Instrumentos de análise para utilização no método dos cenários: I - análise estrutural. Lisboa: Dinâmia.

Rish, I. (2001). An empirical study of the naïve Bayes classifier. Proceedings of the International Joint Conference on Artificial Intelligence, 17, Seattle, USA.

Ritchey, T. (2002). General morphological analysis: a general method for non-quantified modelling. Recuperado em 20 de abril, 2007, de http://www.swemorph.com/pdf/gma.pdf

Ritchey, T. (2005). Futures studies using morphological analysis. Recuperado em 20 de abril, 2007, de http://www.swemorph.com/pdf/futures.pdf

Sandnes, F. E., \& Sinnen O. (2004). Stochastic DFS for multiprocessor scheduling of cyclic taskgraphs. Proceedings of the International Conference on Parallel and Distributed Computing: Applications and Technologies, 5, Singapore. 
Schnaars, S. P. (1987). How to develop and use scenarios. Long Range Planning, 20(1), 105-114.

Schwartz, P. (2000). A arte da visão de longo prazo: planejando o futuro em um mundo de incertezas (4a ed.). São Paulo: Best Seller.

Wack, P. (1985a, September-October). Scenarios: uncharted waters ahead. Harvard Business Review, 63(5), 72-89.

Wack, P. (1985b, November-December). Scenarios: shooting the rapids. Harvard Business Review, 64(6), 139-150. 